\title{
Back to the core: \\ A network approach to bolster harm reduction among persons who inject drugs
}

\author{
Martin Bouchard* \\ School of Criminology, Simon Fraser University, \\ 8888 University Drive, Burnaby, BC, V5A 1S6 \\ Phone: (1) 778-782-8135 \\ mbouchard@sfu.ca \\ Sadaf Hashimi \\ Rutgers University \\ Center for Law and Justice, \\ 123 Washington Street, Newark, NJ 07102-3094 \\ Kristen Tsai \\ School of Criminology, Simon Fraser University, \\ 8888 University Drive, Burnaby, BC, V5A 1S6 \\ Hugh Lampkin \\ Vancouver Area Network of Drug Users \\ 380 East Hastings Street, Vancouver BC, V6A 1P4 \\ Ehsan Jozaghi \\ School of Population and Public Health, Faculty of Medicine \\ University of British Columbia, \\ 2329 West Mall, Vancouver, BC Canada V6T 1Z4 \\ And \\ BC Centre for Disease Control \\ 655 West 12th Avenue \\ Vancouver, BC V5Z 4R4 Canada

\section{Pre-publication version}

Published in: International Journal of Drug Policy, 51, 95-104.

http://dx.doi.org/10.1016/j.drugpo.2017.10.006

Acknowledgements. This work was supported by a grant from the Simon Fraser University's Steel Endowment Fund (2014s0441) and the Canadian Institute of Health Research Postdoctoral Fellowship (201511MFE-358449-223266). We like to thank the PHS Community Services Society, and VANDU who provided access to their peers, clients and resources. Moreover, we would like to thank the individuals who directly or indirectly contributed to this research project, in particular, we would like to thank Marion Allart, Aiyanas Ormond, Darwin Fisher, Russ Maynard, Owen Gallupe and Martin A. Andresen. 


\title{
Back to the core: A network approach to bolster harm reduction among persons who inject drugs
}

\begin{abstract}
Background. Injecting drugs safely almost always includes the presence of one's social network, especially for the prevention of overdose. Yet, the systematic analysis of users' social networks has yet to be established as a focal method in harm reduction research, and interventions.
\end{abstract}

Methods. This study draws from 200 interviews with persons who inject drugs recruited from North America's first sanctioned supervised injection facility and a drug user's advocacy group. Respondents were asked about the individuals they personally considered as facilitators of harm reduction, and the relations between themCollectively, these 200 respondents provided over 900 individuals whom they considered as members of their harm reduction network. The aim was to locate individuals that would potentially make the network denser (harm reduction champions) and users that were situated in the "periphery" of the network, and in practice, further away from the harm reduction core.

Results. Results found that 63 individuals formed the "core" of the harm reduction network, collectively reaching approximately $70 \%$ of individuals in the network. We also uncovered 31 individuals that acted as "articulation points"- these individuals were not as connected, but were more effective at reaching peripheral individuals.

Conclusion. The PWIDs we sampled were surrounded by a relatively rich harm reduction network, but the network approach showed that only a minority of individuals were true harm reduction "champions". Recruitment of a combination of well-connected harm reduction 
champions, and strategically connected articulation points, would be most effective in planning network interventions that encourage harm reduction behaviors among this population.

Keywords: Canada; Social network analysis; Harm reduction; Peers; Persons who inject drugs; Downtown Eastside; Core-periphery.

\section{Introduction}

Injecting drugs safely almost always involves the presence of others, especially for the prevention of overdose. Intervention efforts are most effective when we treat the networks of persons who inject drugs (PWIDs) as mechanisms for delivering services, education, and strategies to members embedded in their own social injection networks. Yet, while injection networks serve as a mechanism for support, they may also facilitate at-risk behaviors that are a source of health-related risks. Network methods provide opportunities to understand the flow of infectious diseases, insights into the at-risk behaviors of drug users, and a means to map the transmission of practices of safe behavior amongst drug users (Latkin et al., 1993; Klovdahl et al., 1994; Curtis et al., 1995; Friedman et al., 1997; Suh et al., 1997; Weeks et al., 2002; ). Harm reduction behaviors are not independent of the types of social exchange and interpersonal relationships that surround PWIDs. The use of harm reduction behaviors is associated with both the perceived acceptance, as well as the use of such practices by other injectors in one's social network (Unger et al., 2006; Andia et al., 2008; Hawkins et al., 1999).

This study draws from 200 interviews with PWIDs in Vancouver's Downtown Eastside (DTES) from a supervised injection facility and a drug users' advocacy group. Respondents were asked about the individuals they personally considered as facilitators of harm reduction, and the connections between them. The research design allowed us to map an important slice of the harm 
reduction amongst PWIDs in the DTES. Mapping the network of a relatively hidden phenomenon provides a unique opportunity to uncover its social structure. Are some PWIDs well supported and part of a harm reduction "core"? Alternatively, are some users isolated from others, situated on the periphery of the network? The aim is to identify individuals that could help bring peripheral users back to the core of the harm reduction network.

\section{Background}

In 2003, InSite, North America's first sanctioned supervised injection facility was opened in the DTES, operating under a constitutional exemption. InSite has been subjected to dozens of peerreviewed studies (Potier et al., 2014). The results of these studies have been overwhelmingly positive: Reduction in the human immunodeficiency (HIV) and hepatitis $\mathrm{C}$ (HCV) viruses in the DTES population, overdoses, public drug use, publicly discarded syringes and syringe sharing and risky injecting practices (e.g. Kerr et al., 2005; Marshall et al., 2011; Wood et al., 2003; Milloy et al., 2008; Markwick et al., 2014).

One of the issues emerging from these studies, however, is that supervised injection sites are unable to supply even close to the daily harm reduction needs of drug users in the area. For instance, in the early 2000's it was reported that there were approximately 8000 injection drug users residing the DTES (Wood et al., 2004). In 2015, InSite reported approximately 263,713 visits to the site by over 6,532 individuals. That is, an average of 722 visits per day across its 13 injection booths (Vancouver Coastal Health, 2017), which is estimated to supply approximately $5 \%$ of the daily needs in the area. The need for additional harm reduction services in the DTES is partly supplied by more informal peer-driven program "networks" that exploit the interpersonal relationships of users (Greer et al., 2016; Jozaghi, 2014; Jozaghi, 2015; Kerr et al., 2006; McNeil et al., 2014; McNeil et al., 2015; Small et al., 2012). Researching the social structure of harm 
reduction is important in understanding the types of users who have direct access to harm reduction mentors or peers, and those users who are relatively isolated from harm reduction services across the informal, network-driven services like the Vancouver Area Network of Drug Users (VANDU), and the more established supervised facilities like InSite.

Empirical studies of this type of population have made use of the conceptual tools offered by network theory. In fact, sharing behaviors are found to be reflective of peer influences, and social norms, that are practiced in ones' network (Andia et al., 2008). Network characteristics such as the size, density, and quality of relationships have been used to examine exposure to harm reduction or at-risk behaviors (Cox et al., 2008; Andia et al., 2008; Gyarmathy et al., 2009; Booth et al., 2016; Hoffman et al., 2013; Latkin et al., 1993). For instance, across a sample of PWIDs, Andia et al. (2008) found that norms encouraging at-risk behaviors such as believing it is okay to share paraphernalia resulted in an increase in paraphernalia sharing. Alternatively, if PWIDs observed their peers participating in HIV-related safe behaviors (always cleaning needles before use), they were likely to report lower frequencies of HIV-related risk behaviors (unclean needle sharing) and increased frequency of HIV-related safe behaviors (Hawkins et al., 1999).

Network composition may also act as both a protective and risk factor. Klovdahl (1994) focused on how the structural properties of networks impacted the ways in which infectious agents were spread among a population of prostitutes and injecting drug users in Colorado. His findings demonstrated how small changes in practices of safe behaviors not only affected the immediate, personal, network of the individual, but also persons in the larger network, indirectly connected to that individual. Similarly, changes in relationships affect risk-taking behaviors and the establishment of behavioral norms. 
Weeks et al. (2002) and Booth et al. (2016) both advocated for peer educators, showing the extent to which peers can influence the prevalence of at-risk behaviors (HIV incidence rates; diffusion of safe behaviors) in their social networks. Weeks et al. (2002) examined how HIV prevention techniques implemented in high-risk sites could diffuse along the network of drug users. Peer educators proved to be the most effective means for diffusing prevention information and materials through the network with the placement of 14 peer educators reaching $50 \%$ of drug users in the largest component. In a randomized trial of PWIDs, Booth et al. (2016) found a reduction in HIV incidence rates in the network of peers that were encouraged to provide safe behavior interventions, and skills training, to members of their own network on how to reduce HIV risk behaviors, relative to the control condition.

While injecting in public, decreases the probability of overdose, injecting in public settings (e.g. shooting galleries, cars), surrounded by a network of others, is also related to frequent and receptive syringe sharing (Cox et al., 2008) and other paraphernalia (Thiede et al., 2007). Larger, less dense networks, have conventionally been associated with higher levels of needle sharing (Latkin et al., 1996) and risky sexual behaviors such as multiple partners, exchanging drugs or money for sex and sex with an unknown partner (Latkin et al., 1993). Network interventions, when employed, are most efficient when they encourage risk reduction communication, and discourage communication among network members that would promote risk behaviors (Gyarmathy et al., 2009, p. 5).

The current study exploits the peer based nature of the network design. By highlighting central individuals in the harm reduction network, we propose to use these individuals as conduits that bring peripheral users closer to the core of the network. The objective was to map the social structure of the harm reduction behaviors, and to uncover individuals who are most 
likely to reduce the distance between the most vulnerable PWIDs and the harm reduction core. A harm reduction network, if implemented through peer-educators, has the power to reach a population of drug users who may not be able to (or feel comfortable) accessing harm reduction initiatives by providing access and knowledge to: supplies (new syringes, new needles, alcohol swabs etc.), conventional health care services, shelters, housing services, income centers, food, and access to centers tailored to their community. Seeking focal individuals that have influence over network members' behaviors is a strategic, and potentially a more efficient approach (this study is a first step, the approach has not been implemented yet), to diffusing positive behavioral change across a difficult to reach population (Booth et al., 2016; p.2).

\section{Data and methods}

\section{Data collection sites and peer recruitment}

InSite opened in 2003. It is North America's first legally sanctioned supervised injection facility located in Vancouver, B.C. VANDU was founded in 1998. It brings together drug users from an adjacent area, and encourages practices of safe behaviors by providing users the opportunity to design and implement harm reduction interventions through peer-based models. VANDU has historically operated through peer-based unsanctioned syringe exchange, supervised injection and smoking rooms (Wood et al., 2003; McNeil et al., 2014; McNeil et al., 2015).

Peers, often current or ex-injecting drug users themselves, are well-connected to the community of injecting drug users in the area. They act as outreach workers, employed in various harm reduction programs, and serve as gateways to avid users by conveying harm reduction materials and information that deliver messages of safe behaviors. At InSite, peers are actively involved in the "chill lounge," whereas at VANDU, injections are supervised by members of the community with experience in safe injecting practices. 
This research was approved by the PHS Community Services Society and VANDU's executive board. Approval was also granted by both the Vancouver Coastal Health and Simon Fraser University's Research Ethics Boards. The recruitment method was inspired by respondent driven sampling (RDS) techniques ${ }^{1}$, a method of chain referral sampling derived from the mathematical modeling of Markov chains (Heckathorn, 1997; Malekinejad et al., 2011). The research design relied on peers as recruitment agents for the study, following a snowball sampling method. Initially, 10 peers, per site, were given the opportunity to recruit 10 persons who injected drugs (respondents). While this technique was followed at Insite (10 peers recruited 10 respondents, $n=100$ ), it was more challenging to find 10 peers who could recruit 10 others who had not already participated in the study at VANDU. Of the six peers who recruited respondents at VANDU, four recruited 10 respondents each, one recruited 14 respondents, and another recruited 46 respondents in total $(\mathrm{n}=100)$ for a total of 200 PWIDs. Respondents provided informed consent. Peers and respondents would meet with the interviewer, who had a designated private room for interviews at each of the study locations, to administer the survey.

\section{Survey and respondent characteristics}

The survey comprised two components. First, respondents provided anonymized information on their own self-reported characteristics such as their age, sex, marital status, racelethnicity, sexual preference, and education, the latter having been recoded as a dichotomous variable for high school completion. The descriptive statistics for the sample of 199 respondents, and direction of the coding for all variables used in this study are found in Table 1. Respondents were also asked about their criminal history, medical history, and their habits of drug use. The medical history variables of interest were whether respondents were $H C V$ positive, or HIV positive. Questions on

\footnotetext{
${ }^{1}$ We were unable to implement a strict RDS protocol that would have allowed us to use inferential statistics on the larger population from which our sample is drawn. The extent to which our sample is representative of PWIDs in the DTES remains unknown and a limitation of the study.
} 
drug use included their drug of choice (we focus on heroin, the most prevalent category), whether they ever overdosed, whether they always use new needles to inject drugs, mean number of years injected, mean number of weekly injections, and money spent on drugs, weekly (natural $\log$ to correct for skewness in the distribution).

\section{TABLE 1 ABOUT HERE}

Table 1 shows that respondents from InSite and VANDU shared the same basic characteristics. Respondents were, on average, 44.5 years old. Of the 199 respondents, $61.3 \%$ were males, $59.8 \%$ were Caucasian, and $94 \%$ were heterosexual. Over half of the respondents had a high school degree, but were largely unemployed (68.3\%). Approximately $79 \%$ of the sample had a criminal record. In terms of drug use and medical history, most respondents preferred heroin with $81.4 \%$ reporting it as their drug of choice. On average, respondents reported 17.5 years of injected drug use $(S D=12.10$, median $=15.0)$, with 42.3 mean injections per week $(\mathrm{SD}=43.60$; median=28.0), and spent, on average, $\$ 905.93$ (median= $\$ 525.00)$ on drugs, per week. The prevalence of HIV and HCV amongst the population, however, varie: 13.1\% ( $\mathrm{SD}=0.34)$ were $\mathrm{HIV}$ positive, and $53.8 \%$ of the sample had HCV ( $\mathrm{SD}=0.50)$. The only statistically significant difference between respondents from the two sites were the higher proportion of males (70\%) from InSite, compared to VANDU (52.5\%).

The second component of the survey mapped the personal network of each respondent. Respondents were asked to nominate up to 10 of their closest contacts with whom they engaged in harm reduction practices with. That is, those who they received harm reduction supplies from and practiced other types of safe behaviors with in the last 12 months. $^{2}$ One respondent did not

\footnotetext{
${ }^{2}$ These roles included: told me about detox; taught me how to fix drugs properly; told me about Insite, VANDU, or a Drug users' resource center; provided syringes, alcohol swaps, ties, filters; referred me to a nurse or a doctor; referred me to a homeless shelter; referred me to a place where I could get food; referred me to a pharmacy where I could get methadone; provided food, coffee, juice or water; performed CPR when I/or someone overdosed;
} 
provide any network information, and was excluded from the analyses presented in this study (n $=199$ ). Respondents provided their contacts name and perceived attributes such as age, sex, and length of relationship. They were also asked to indicate which of the contacts in their personal network knew each other, and provided information about their contacts perceived behaviors such as: years of drug use, drug of choice (we focus on heroin) and if they still use drugs, whether the respondent considered the contact as a mentor, defined as an individual who taught them, advised them, and/or were held in high-esteem, and their medical condition (HCV positive, and HIV positive) $)^{3}$.

Table 2 provides an overview of the 1025 contacts (which includes respondents, to the extent that they were named as contacts by others). On average, respondents were older than their contacts (44 v. 40 years old). Of the 1025 contacts, $60.1 \%$ were males, $75.6 \%$ used drugs at time of survey, with on average 13 years of prior drug use, $56.9 \%$ preferred heroin as their drug of choice and $19.6 \%$ of contacts were reported as never using drugs ${ }^{4}$. Approximately $24 \%$ of contacts were considered as a mentor by the respondent, with respondents reporting $11.4 \%$ of their contacts as HIV positive, and $29.5 \%$ as $\mathrm{HCV}$ positive. We found significant differences across the two sites, with many of these differences emerging from the subsample of 153 contacts who were named by respondents from both the InSite and VANDU. These contacts

administered Narcan when I/or someone overdosed; called ambulance for help when I/someone overdose; provided harm reduction education; broke up fight at injection room; talked to me and asked how I was doing; know me by first name; came with me to hospital, referred me to a social worker, other (specify)

${ }^{3}$ This question was presented in three parts, the first part comprised "I would now like to ask you [...] about contacts where you get your harm reduction supplies." The second part reminded respondents that attributes are based on their perception "please note that any information you provide [...] such as their medical condition, years of drug use or the drug they use is based on your belief. This information may not be based on the actual fact" The third part asked "In the past 12 months, what is the role that [...] has been involved in?" (see footnote 2 for a list of roles)

${ }^{4}$ Unlike the respondents who had to be a former or current drug-user to participate in the survey ( $\left.\mathrm{n}=199\right)$, respondents were able to name contacts that were not current or former users, but those who facilitated, or they engaged in harm reduction behaviors with. Of the 1025 contacts, $19.6 \%$ were reported as never using drugs. 
were generally perceived to be current heroin users, more likely to be HCV or HIV positive, and more likely to be named as mentors by the study participants.

\section{TABLE 2 ABOUT HERE}

\section{Network formation}

A primary objective of the study was to map the harm reduction network in the DTES (from the point of view of the 199 respondents). To construct the network, we systematically identified and verified the network ties amongst network members. Thus, a critical methodological step involved cross-network matching, that is, matching contacts named by individual respondents across the entire set.

Given the absence of a roster, and the hidden nature of the population under study, we needed a procedure to recognize when John Doe, as named by respondent A, was the same John Doe named by respondent B. The procedure to match and merge contacts who appeared to be one and/or the same involved a few assumptions. First, we had the names of the contacts, most often only the first name or known nickname, and a series of attributes for each contact, as reported by respondents. The most straightforward matches occurred in instances where the full names and attributes matched perfectly, but this was relatively rare. In cases where network participants had the same, or similar names ${ }^{5}$, we used various proxies, at the individual level, to systematically, identify, and distinguish between participants. We used attributes such as reported age (within 10 years), sex, drug of choice, whether they still used drugs, years of drug use (within 5 years), site that they were based from, and medical condition to match individuals. It was necessary that participants match on at least four indicators: sex, age, where their reported age was within 10 years from one another though we recognize that age may not be linear and

\footnotetext{
${ }^{5}$ By similar names we refer to situations where individuals would be identified, in various ways, for instance by their full names, nick names, or common names such as Bobby, Bob, Robert; Richard, Dick, Richy; Sam, Samuel, Samantha, etc. in addition to instances where names would be misspelled for instance Aron, Arron, Aren
} 
perceptions vary across age range, whether they were reported as a current drug user, and their drug of choice. The other three variables (years of drug use, site, medical condition) were used for cases where there were further discrepancies, and to validate the initial decision.

The second challenge with this process was that these reported attributes were based on the perception that respondents had of their contacts, not their contacts self-reports, which can lead to inconsistencies. Previous studies have measured the reliability of self-reports by evaluating the level of agreement between pairs of PWIDs. These studies found that PWIDs, as a group, tend to reliable, truthful and accurate in their self-reports, and observed reports (Goldstein et al.,1995; Darke et al., 1991; Padian, 1990). For instance, Goldstein et al (1995) compared selfreport data of PWIDs to that of another PWIDs in their network, namely a contact who the subject shared behaviors with (drug-related, sexual), to determine how well matched the pairs' responses were. Subjects reported on their contacts demographic characteristics (age, gender, race/ethnicity), several shared and observed behaviors (risky sexual, drug-use behaviors) and estimated years of injection. They found that PWIDs were reliable reporters of their own behaviors (HIV; years of injection, demographics) as well as their contacts behaviors with a relatively high level of agreement between the subject's estimation and contacts self-report.

With both the cross-network matching, and accuracy of respondent's report, we were unable to verify the accuracy of these reports with the contacts, nor were respondents always able to provide this type of descriptive information about their network. This implied that we could fail to make a match if these attributes did not match perfectly, even if two, or more, respondents were referring to the same individual. If we applied too strict of a set of criteria for the matching, we could get many false negatives; and if we applied a set of criteria that were too lenient, we would get many false positives. In this instance, given the relatively homogenous 
nature of the sample (gender, drug use, drug of choice) we risk having a number of false positives. We took several steps to minimize. The matching procedure was cross-validated between researchers whereby the networks were compared to see where discrepancies occurred. These cases were discussed to maximize intercoder reliability and intercoder agreement. Furthermore, we relied on the interviewer's direct relationship with peers and respondents (a single interviewer with prior research experience in the DTES interviewed all respondents), expertise, and physical presence at the two sites to facilitate follow-up tracking, and help verify cross-network membership. These steps provided consistency and reproducibility whereby the decision scheme and knowledge of one researcher could be applied equally to another researcher (Campbell et al., 2013) minimizing the implications and maximizing the accuracy of matches.

Without the matching process, we would have a network of 199 respondents, and their 10 contacts (most respondents named 10 contacts), totaling 1888 contacts. Of the 1888 initial contacts, we took a probabilistic approach with $65.6 \%$ of contacts either by matching, or differentiating between, contacts with the same names and attributes. This resulted in a sample of 1025 contacts whereby 735 were treated as isolates, named as a contact only once, and 290 contacts were merged, named by two or more respondents. Once the matching process was completed, we faced the challenge of selecting which attributes to assign duplicate persons. That is, in instances where attributes, for two or more cases, were not all similar. For quantitative variables (age, years of drug use), we used the mean across cases. For nominal variables (drug of choice, medical condition), we used the most frequently reported response. In case of a tie, we leaned towards a conservative approach, and did not code for the presence of the attribute. This step, again, was cross validated by two researchers. 
This lead to a final network of 1135 unique network members, including 110 respondents that reported being current or former drug-users but were not named by any other as a harm reduction contact, and 75 former or current users that had the dual role of respondent and contact. Among the 16 peer recruiters, 14 took the survey and the remaining two peers were named as contact by at least one respondent. The bulk of the network comprised 934 contacts who were either former users, current users or pure social contacts (never used) and were named by at least one network member as having facilitated harm reduction behaviors, but did not act as a peer recruiter or respondent.

\section{Analytic Strategy}

The analysis proceeds in three steps. First, we provide descriptive measures for the network structure. Second, we apply a core-periphery algorithm to the data. A network is said to have a core-periphery structure when a relatively small (relative to network size) group of nodes have a high density of links, highly connected to each other (and in general), and connected to the periphery, though the latter are not highly connected to the core or to one another (Borgatti \& Everett, 1999; Rombach et al., 2014). In other words, the core should be a relatively dense group that also reaches out to peripheral actors. Within the context of the current study, the goal is to uncover 1) whether there is a core group of individuals that stand out, relative to others, in terms of their connections and hence their exposure to harm reduction efforts and 2) if this group could be exploited to reach an important proportion of the network, for instance, users that are most peripheral (and furthest from the core) and have less accessibility to harm reduction efforts.

Borgatti and Everett (1999) developed discrete, and continuous models of core/periphery analyses. We tested the suitability of a few algorithms, and selected the continuous "coreness" algorithm based on the MINRES (for "minimum residual method" from Comrey 1962) factor 
analytic approach (applied to nodes, as opposed to variables) (Borgatti \& Everett, 1999). The coreness score behaves like a standard centrality measure in that individuals with a high coreness score tend to be highly connected. Yet, given the requirement that core members be highly connected to one another, as a group, not all highly connected individuals qualify. The actual size of the core is based on the size combination providing the highest correlation (compared to an ideal core-periphery structure).

The third step in our analysis involves finding the articulation points in the data. Articulation points (or cut points) are nodes that hold the network together as one connected component. An articulation point increases the number of connected components in the network. The algorithm iterates across all nodes in the graph, detecting every edge in the network, and flagging repeated edges to the node to the degree that the node would become disjointed if all edges were removed. Articulations points, relative to other nodes, have multiple edges connecting to it, thus, if removed articulation points increase the number of disconnected components in the network, making it impossible for nodes in separate components to communicate, or in this context, transmit practices of safe behaviors, or harm reduction efforts, with one another (Wasserman \& Faust, 1994). The position of these nodes makes them easily identifiable as they are typically found toward the edges of the network. In the harm reduction network, nodes that act as articulation points are strategic. First, they act as a harm reduction lifeline, as they are potentially the only access point to users who would, otherwise, be disconnected from the main network. Second, from the perspective of trying to bring vulnerable users to the core, articulation points become key nodes upon which to rely on to make this happen. We use UCINET (Borgatti \& Everett., 1999) for all analyses, and Organizational Risk Analyzer (Carley et al., 2013) for network visualization. 


\section{Results}

Figure 1 provides a visual representation of the main component of the network ${ }^{6}$. There emerges a dense center, which comprises many of our respondents, especially the 75 respondents who had the dual role of respondent, and contact. Towards the periphery of the network are contacts, generally named by a single respondent. The main component of the network comprised 1131 nodes, 14438 ties between nodes, a density of 0.011 ( $1.1 \%$ of all possible ties are present) and a mean nodal degree of 12.77 . These measures are heavily influenced by the research design, which asked every respondent to name up to 10 of their contacts. It is when similar alters are named that the network begins to divert from a simple structure of 199 star-like networks of 11 nodes (ego and 10 alters), to the fully connected network shown in Figure 1.

The core-periphery analysis suggests that the network can be broken down into a core of 63 nodes, and a periphery of 1068 nodes. The core included a minority (5.6\%) of highly connected nodes, who had 6 times as many connections in comparison to peripheral nodes (mean degree $=59.7$ for the core vs. 10.0 for the periphery). The core itself had a density of $30.4 \%$, which is much higher than the density within the periphery $(0.7 \%)$. As expected, the group of 63 core nodes are connected to the periphery at a higher rate (3.8\%) than the periphery to itself. Core members, identified by the circles, can be easily spotted in the middle of the graph.

\section{FIGURE 1 ABOUT HERE}

\section{TABLE 3 ABOUT HERE}

Of the 199 respondents, 22 were part of the core group, including 11 peers who had both roles (1 more peer was in the core, but not a respondent). In total, 40 members of the core were not respondents or peers in the study but were repeatedly named as contacts who had helped provide

\footnotetext{
${ }^{6}$ One respondent and his network of three facilitators of harm reduction $(n=4)$ was not connected to anyone else in the network. All four individuals were removed to facilitate network measurements, and interpretations.
} 
harm reduction services. This is an important finding, as these 40 individuals were not initially identified for recruitment. Yet, they would be important individuals to recruit to spread harm reduction to users that are most isolated in the network.

Table 3 presents the characteristics of core members. Beyond centrality measures, core members are important drivers of harm reduction in the DTES. They are relatively older (44 vs. 40 years old on average), more likely to be male, heroin users, HCV positive, and to have been named as a specific harm reduction mentor by other users ( $73 \%$ vs. $18 \%$ ). They were not significantly more likely to have quit using drugs, to be HIV positive, or to have had longer drug using careers. Interestingly, core members were more likely to frequent both VANDU and Insite. Bringing vulnerable individuals back to the core

As connected as they are, core members are not necessarily strategically positioned to directly influence the most disconnected, peripheral members of the network, rather the core-periphery analysis exposes a dense cohesive core, and a sparse periphery, whereby core members have multiple pathways to one another. To accomplish the goal of connecting peripheral users to the harm reduction core, we turn to articulation points. Our analysis uncovered 31 articulation points. These articulation points access vulnerable actors more directly than others. If removed, articulation points disconnect users who depend on them to reach the rest of the harm reduction network.

A look at the harm reduction network in Figure 1, whereby articulation points are the triangles, demonstrates their ability to reach the periphery, in comparison to other users, acting as a sort of lifeline for the outer layer. While slightly more connected than the rest of the network (mean degree 18 vs $12, \mathrm{p}<0.05$ ), those connecting to articulation points are dependent. Without their connections, these actors would lose the already limited support network they have for 
harm reduction. As important as they are, however, articulation points do not overlap with core members - a single actor is part of both subgroups (square in the center left of the network, see Figure 1). Table 4 shows that articulation points differ from core actors in numerous ways. First, they are most likely to be female actors ( $60.4 \%$ vs. $38.7 \%$, p<0.05), to be HCV positive, but they are not significantly older than others. They are not more likely to be named as harm reduction mentors by respondents, nor are they more likely to frequent one location (VANDU or InSite) than the other. Like core actors, articulation points are more likely to be heroin users, and the majority (29 of 31 ) are actual respondents. HIV status, current drug use, drug use career does not significantly differ for this group. These respondents comprise a unique profile of connections that overlapped little with most other respondents.

\section{TABLE 4 ABOUT HERE}

To better understand the potential for connections, we looked at the extent to which articulation points can reach other users. The 31 articulation points directly reach to $36.8 \%$ of other network members. Table 4 shows that these 416 unique individuals reached by one or more articulation point, in comparison to others, are significantly likely to be heroin users $(65.1 \%$, $\mathrm{p}<0.01)$, likely to report, or be reported, as still using drugs $(82.6 \%, \mathrm{p}<0.001)$ and be considered as a mentor $(26.9 \%, \mathrm{p}<0.01)$. On the other hand, of the 1131 individuals in the network, core members reached $69.4 \%(n=785)$ of the network. By virtue of their centrality, and location in the network, core members have the power to disseminate, and receive, practices of safe behaviors, and preventative efforts, though these linkages are predominately redundant, impacting users that are already exposed to harm reduction efforts. In contrast, individuals reached by articulation points are relatively isolated both in their location and level of incoming resources. If not for articulation points, we lose $7.7 \%$ of ties, and isolate $3.4 \%$ users from the network. That is, 39 
isolates would be created by removing the articulation points. By contrast, removing the 63 core members would only create one isolate (from removing the single core member who overlap with our articulation points), but leads to a loss of $29.2 \%$ of ties in the network. The right side of Table 4 shows the profile of these isolates, who are significantly more likely to be female, and less likely to be HCV positive. Though differences are not statistically significant, the results suggest a younger sub-population, which could partly explain their relative isolation.

\section{Discussion and conclusions}

The DTES, Canada, is home to a host of individuals actively involved in diffusing harm reduction practices. In many ways, it follows a network principle to diffuse the message of safe behaviors to as many PWIDs as possible through InSite (Jozaghi, 2015; McNeil et al., 2014; Small et al., 2012) and VANDU, an informal peer-based network of safe injection practices (Kerr et al., 2006), and several peer engagement programs (Greer et al., 2016). Peer-driven research have been used to effectively recruit difficult to reach populations, expanding the reach of intervention services to those who otherwise would have not been reached (Smyrnov et al., 2012; Valente, 2015) whilst capitalizing on the relationship between former or current users (Heckathorn et al., 2015).

Despite these important, network-informed initiatives, researchers had yet to test the feasibility of collecting systematic network data from PWIDs as means to push network-based research even further. Adopting a network approach, the current study found that most PWIDs were surrounded by a relatively rich harm reduction network, including many harm reduction “champions", or opinion leaders (Valente, 2012). The network we found had a relatively large

and dense core of 63 individuals who had, on average, close to 60 ties in the network, compared to a mean of 10 ties for the periphery. The majority $(n=40)$ of these highly active harm 
reduction champions were not part of the research process, either as peers or as respondents. Yet, they were uncovered by implementing a relatively small study like ours, with a systematic network data collection.

Although this study was not planned as an intervention, it is worth reflecting on the opportunity to replicate the study, with more ambitious, program implementation goals in mind. This study, methodologically, demonstrates the opportunity to seek and empower active or former users to influence their network members, and to shape or change their at-risk behaviors. It is a potentially cost-effective approach to promoting behavioral change across a relatively marginalized, hidden population, that faces public-stigma and are at risk of detection from law enforcement agencies (Booth et al. 2016; Valente, 2015).

While many conditions (environmental, health, situational, and psychological) may explain why some PWIDs engage in harm reduction whereas others do not, social norms are important predictors of harm reduction behaviors (Bonar \& Rosenburg, 2011). The use, and spread of, harm reduction behaviors are contingent on the frequency, perceived acceptance, and the use of these practices by others in one's social network (Unger et al., 2006; Andia et al., 2008; Hawkins et al., 1999). Continuing to re-shape policy, and encourage safe behaviors requires demonstrating how drug users can organize themselves to make valuable contributions to their community, and calls for opportunities for users to observe themselves, and their role in the community, in a more positive and influential light (Kerr et al., 2006).

In many ways, what we propose is part of what Valente et al. (2015) proposes as the fourstage network-based program implementation. The four stages are: 1) exploration or needs assessment; 2) adoption or program design; 3) program implementation, and 4) sustainment and monitoring. The first stage is meant to explore the resources needs of the targeted community, as 
well as assess the social capital it has available to carry an intervention. Our initial efforts at recruiting peers, drawing the experience of multiple key members of the harm reduction community was relatively successful, with 16 recruiters who could convince PWIDs to participate in our study. Yet, it was short of our objective of 20 participants as one peer worked overtime to make sure we attained our objective of 200 respondents.

Granted, our study was exploratory and had limited funding and resources. But the reality, in the field, is that another informal, non-network based effort at recruitment of harm reduction opinion leaders in the DTES would also be likely to hit a wall, sooner or later. The 93 individuals identified through two complementary methods (core-periphery, and articulation points) proposed in this paper would provide a much more relevant starting point for such efforts. What is unknown, however, from our list of 93 individuals who could be recruited, potentially, for intervention, is whether they would have the personality or motivation to help, or even the support of the community. Interventions efforts (see Smith et al., 2017; Booth et al., 2016; Hoffman et al., 2013; Tobin et al., 2011; Booth et al., 2009) aimed at PWIDs emphasize the importance of recruiting the "right" individuals that are backed by community support and resources for a successful intervention (Valente, 2012).

The study comes with limitations and opportunities for future research in this area of study. First, while the main harm reduction network uncovered appears to be relatively large for the DTES at 1131 individuals, it represents the contacts of 199 individuals. Our design does not allow us to generalize our findings to the population of PWIDs in the DTES. Further, the exact size of the population of PWIDs in the DTES is unknown, making a random sample of this hidden, marginalized, population difficult to obtain. The RDS framework should be 
systematically implemented to increase generalizability, and as a means to potentially estimating the size of the population (Heckathorn, 1997).

Second, a limitation of self-reports is the inclination to report socially desirable responses, retention and the accuracy of responses (Krosnick, 1999). There are two specific concerns with that are worth highlighting: 1) we place confidence, and analytical weight, on respondents to accurately report their own, as well, as their perception of their contacts demographic characteristics, harm-reduction practices, and medical conditions; and 2) we use these characteristics to merge persons that were mentioned in the study on more than one occasion. We opted for a relatively conservative approach but it remains difficult to assess the implications of our assumptions and preference for false negatives (i.e. when in doubt, do not match individuals even if they have similar first names) on network outcomes.

We took various measures to substantially increase the internal and external validity of these data. First, we did not match similar names if respondents provided vastly different attributes to describe them, which may have created false negatives. The implication of having false negatives is an inflated network size and decreased density. Although we find this possibility less likely, given the homogenous nature of the sample, it cannot be excluded that our matching procedure also created false positives which would have the opposite effect on the network. Both possibilities may impact the results of the core-periphery analysis, and articulation points, for instance, identifying more peripheral individuals than there are or, alternatively, assigning more edges to a "matched" individual isolating them as an articulation point or part of the "core". Second, to ensure researcher validity, reliability and reproducibility of data, we employed cross-validation techniques, comparing results across two researchers. Third, to decrease erroneous responses, socially desirable responses, or respondent fatigue we distributed 
surveys to participants on-site with the assistance of an on-site employee. This has been found to build rapport between researchers and respondents, increasing respondent accountability, and gives researchers the opportunity to clarify and articulate survey questions that may be hard to understand for a subset of respondents that come from various socio-economic environments, educational backgrounds, or societal contexts. These measures improve both construct and criterion validity (Krosnick, 1999; Junger-Tas \& Marshall, 1999). Finally, constructing a network from a sample implies that the importance or centrality of any network members needs to be interpreted from the point of view of the sample itself. For example, the peripheral members of this network could become central participants if another sample of 200 users were to be taken.

Despite these limitations, our general methods, results, and conclusions still apply. Network methods allow us to identify both key individuals for intervention purposes, and peripheral individuals that may be vulnerable and in need of attention. For practical purposes, given how connected our peers are, and the size of the network, we would be surprised to find drastically different results than the ones we uncovered here. Thus, we can use the methods proposed in the current study to uncover both central, and vulnerable participants, and further design intervention strategies that utilize core members to bolster harm reduction, and decrease many of the health consequences associated with drug use in these areas (see Booth et al., 2016; Tobin et al., 2011; Booth et al.,2009). This appears to be especially urgent given the current opioid crisis facing many communities in North America. 


\section{References}

Andía, J.F., Deren, S., Robles, R.R., Kang, S. Y., Colón, H.M., (2008). Peer norms and sharing of injection paraphernalia among Puerto Rican injection drug users in New York and Puerto Rico. AIDS Education \& Prevention, 20(3), 249-257.

Booth, R. E., Davis, J. M., Dvoryak, S., Brewster, J. T., Lisovska, O., Strathdee, S. A., \& Latkin, C. A. (2016). HIV incidence among people who inject drugs (PWIDs) in Ukraine: Results from a clustered randomised trial. The Lancet HIV, 3(10), e482-e489.

Booth, R. E., Lehman, W. E., Latkin, C. A., Brewster, J. T., Sinitsyna, L., \& Dvoryak, S. (2009). Use of a peer leader intervention model to reduce needle-related risk behaviors among drug injectors in Ukraine. Journal of Drug Issues, 39(3), 607-625.

Bonar, E.E., Rosenberg, H., (2011). Using the health belief model to predict injecting drug users' intentions to employ harm reduction strategies. Addictive Behaviors, 36(11), 1038-1044.

Borgatti, S.P., Everett, M.G., (1999). Models of core/periphery structures. Social Networks, 21(4), 375-395.

Campbell, J. L., Quincy, C., Osserman, J., \& Pedersen, O. K. (2013). Coding in-depth semistructured interviews: Problems of unitization and intercoder reliability and agreement. Sociological Methods \& Research, 42(3), 294-320.

Carley, K. M., Reminga, J., Storrick, J., Pfeffer, J., and Columbus, D. (2013). ORA user's guide 2013. Carnegie Mellon University, School of Computer Science, Institute for Software Research, Technical Report, CMU-ISR-13-108.

Comrey, A.L., (1962). The minimum residual method of factor analysis. Psychological Reports, $11(1), 15-18$. 
Cox, J., De, P., Morissette, C., Tremblay, C., Stephenson, R., Allard, R., Graves, L., \& Roy, É. (2008). Low perceived benefits and self-efficacy are associated with hepatitis $C$ virus (HCV) infection-related risk among injection drug users. Social Science \& Medicine, 66(2), 211-220.

Curtis, R., Friedman, S.R., Neaigus, A., Jose, B., Goldstein, M., Ildefonso, G., 1995. Street-level drug markets: Network structure and HIV risk. Social Networks, 17(3-4), 229-249.

Darke, S., Hall, W., Heather, N., Ward, J., \& Wodak, A. (1991). The reliability and validity of a scale to measure HIV risk-taking behaviour among intravenous drug users. AIDS, 5(2), 181-186.

Friedman, S.R., Neaigus, A., Jose, B., Curtis, R., Goldstein, M., Ildefonso, G., Rothenberg, R.B., Des Jarlais, D.C. (1997). Sociometric risk networks and risk for HIV infection. American Journal of Public Health, 87(8), 1289-1296.

Goldstein, M. F., Friedman, S. R., Neaigus, A., Jose, B., Ildefonso, G., \& Curtis, R. (1995). Self- reports of HIV risk behavior by injecting drug users: are they reliable. Addiction, 90(8), 1097-1104.

Gyarmathy, V. A., Li, N., Tobin, K. E., Hoffman, I. F., Sokolov, N., Levchenko, J., Batluk, J., Kozlov, A.A., Kozlov, A.P. \& Latkin, C. A. (2009). Correlates of unsafe equipment sharing among injecting drug users in St. Petersburg, Russia. European Addiction Research, 15(3), 163-170.

Hawkins, W.E., Latkin, C., Mandel, W. \& Oziemkowska, M. (1999). Do actions speak louder than words? Perceived peer influences on needle sharing and cleaning in a simple of injection drug users. AIDS Education and Prevention, 11(2), 122-131. 
Heckathorn, D.D. (1997). Respondent-driven sampling: a new approach to the study of hidden populations. Social Problems 44(2), 174-199.

Hoffman, I. F., Latkin, C. A., Kukhareva, P. V., Malov, S. V., Batluk, J. V., Shaboltas, A. V. Skochilov, R.V., Sokolov, N.V., Verevochkin, S.V., Hudgens, M.G. \& Kozlov, A. P. (2013). A peer-educator network HIV prevention intervention among injection drug users: results of a randomized controlled trial in St. Petersburg, Russia. AIDS and Behavior, 17(7), 2510-2520.

Jozaghi, E. (2014). The role of drug users' advocacy group in changing the dynamics of life in the Downtown Eastside of Vancouver, Canada. Journal of Substance Use, 19(1-2), 213218.

Jozaghi, E. (2015). Exploring the role of an unsanctioned, supervised peer driven injection facility in reducing HIV and hepatitis $\mathrm{C}$ infections in people that require assistance during injection. Health \& Justice 3(1), 1-10.

Junger-Tas, J., Marshall, I.H. (1999). The self-report methodology in crime research. Crime and Justice 25, 291-367.

Kerr, T., Small, W., Peeace, W., Douglas, D., Pierre, A., Wood, E. (2006). Harm reduction by a “user-run" organization: a case study of the Vancouver Area Network of Drug Users (VANDU). International Journal of Drug Policy, 17(2), 61-69.

Kerr, T., Tyndall, M., Li, K., Montaner, J.S.G., Wood, E. (2005). Safer injection facility use and syringe sharing in injection drug users. Lancet, 366(9482), 316-318.

Klovdahl, A.S., Potterat, J.J., Woodhouse, D.E., Muth, J.B., Muth, S.Q., Darrow, W.W. (1994). Social networks and infectious disease: The Colorado Springs study. Social Science and Medicine, 38(1), 79-88. 
Krosnick, J.A. (1999). Survey research. Annual Review of Psychology, 50(1), 537-567.

Latkin, C., Mandell, W., Oziemkowska, M., Vlahov, D., \& Celentano, D. (1993). The relationships between sexual behavior, alcohol use, and personal network characteristics among injecting drug users in Baltimore, Maryland. Sexually Transmitted Diseases, 21(3), 161-167.

Latkin, C. A., Mandell, W., Vlahov, D., Oziemkowska, M., \& Celentano, D. D. (1996). The long- term outcome of a personal network- oriented HIV prevention intervention for injection drug users: The SAFE study. American Journal of Community Psychology, 24(3), 341-364.

Malekinejad, M., McFarland, W., Vaudrey, J., Raymond, H.F. (2011). Accessing a diverse sample of injection drug users in San Francisco through respondent-driven sampling. Drug and Alcohol Dependence, 118(2-3), 83-91.

Markwick, N., Ti, L., Callon, C., Feng, C., Wood, E., Kerr, T. (2014). Willingness to engage in peer-delivered HIV voluntary counselling and testing among people who inject drugs in a Canadian setting. Journal of Epidemiology and Community Health, 68, 675-678.

Marshall, B.D.L., Milloy, M.J.S., Wood, E., Montaner, J.S.G., Kerr, T. (2011). Reduction in overdose mortality after the opening of North America's first medically supervised safer injection facility: A retrospective population-based study. Lancet, 377(9775), 1429-1437.

McNeil, R., Kerr, T., Lampkin, H., Small, W. (2015). "We need somewhere to smoke crack": an ethnographic study of an unsanctioned safer smoking room in Vancouver, Canada. International Journal of Drug Policy, 26(7), 645-652.

McNeil, R., Small, W., Lampkin, H., Shannon, K., Kerr, T. (2014). "People knew they could come here to get help": An ethnographic study of assisted injection practices at a peer-run 
'unsanctioned' supervised drug consumption room in a Canadian setting. AIDS Behavior, $18(3), 473-485$.

Milloy, M.J.S., Kerr, T., Tyndall, M., Montaner, J.S.G., Wood, E. (2008). Estimated drug overdose deaths averted by North America's first medically-supervised safer injection facility. PLoS ONE, 3(10): e3351, 1-6.

Padian, N. S. (1990). Sexual histories of heterosexual couples with one HIV-infected partner. American Journal of Public Health, 80(8), 990-991.

Potier, C., Laprévotec, V., Dubois-Arbere, F., Cottencina, O., Rollanda, B. (2014). Supervised injection services: What has been demonstrated? A systematic literature review. Drug and Alcohol Dependence, 145(1), 48-68.

Rombach, M.P., Porter, M.A., Fowler, J.H., Mucha, P.J. (2014). Core-periphery structure in networks. SIAM Journal on Applied Mathematics, 74(1), 167-190.

Small, W., Wood, E., Tobin, D., Rikley, J., Lapushinsky, D., Kerr, T. (2012). The Injection Support Team: a peer-driven program to address unsafe injecting in a Canadian setting. Substance use \& Misuse, 47(5), 491-501.

Smith, L. R., Strathdee, S. A., Metzger, D., \& Latkin, C. (2017). Evaluating network-level predictors of behavior change among injection networks enrolled in the HPTN 037 randomized controlled trial. Drug and Alcohol Dependence, 175, 164-170.

Smyrnov, P., Broadhead, R. S., Datsenko, O., \& Matiyash, O. (2012). Rejuvenating harm reduction projects for injection drug users: Ukraine's nationwide introduction of peerdriven interventions. International Journal of Drug Policy, 23(2), 141-147.

Suh, T., Mandell, W., Latkin, C., Kim, J. (1997). Social network characteristics and injecting 
HIV-risk behaviors among street injection drug users. Drug and Alcohol Dependence, 47(2), 137-143.

Thiede, H., Hagan, H., Campbell, J. V., Strathdee, S. A., Bailey, S. L., Hudson, S. M., Kapadia, F., Garfein, R.S. \& DUIT Study Team. (2007). Prevalence and correlates of indirect sharing practices among young adult injection drug users in five US cities. Drug and Alcohol Dependence, 91, S39-S47.

Tobin, K. E., Kuramoto, S. J., Davey- Rothwell, M. A., \& Latkin, C. A. (2011). The STEP into Action study: A peer- based, personal risk network- focused HIV prevention intervention with injection drug users in Baltimore, Maryland. Addiction, 106(2), 366375.

Unger, J.B., Kipke, M.D., De Rosa, C.J., Hyde, J., Ritt-Olson, A., Montgomery, S. (2006). Needle-sharing among young IV drug users and their social network members: the influence of the injection partner's characteristics on HIV risk behavior. Addictive Behaviors, 31(9), 1607-1618.

Valente, T.W. (2012). Network interventions. Science 337(6090), 49-53.

Valente, T.W., Palinkas, L.A., Czaja, S., Chu, K., Brown, C.H. (2015). Social network analysis for program implementation. PLOS ONE 10(6), 1-18.

Vancouver Coastal Health (2017). Insite user statistics. http://www.vch.ca/public-health/harmreduction/supervised-injection-sites/supervised-injection-user-statistics (accessed 17.05.25)

Wasserman, S., \& Faust, K. (1994). Social network analysis: Methods and applications (Vol. 8). Cambridge university press. 
Weeks, M. R., Clair, S., Borgatti, S. P., Radda, K., \& Schensul, J. J. (2002). Social networks of drug users in high-risk sites: Finding the connections. AIDS and Behavior, 6(2), 193-206.

Wood, E., Kerr, T., Small, W., Li, K., Marsh, D. C., Montaner, J. S., \& Tyndall, M. W. (2004). Changes in public order after the opening of a medically supervised safer injecting facility for illicit injection drug users. Canadian Medical Association Journal, 171(7), 731-734.

Wood, E., Kerr, T., Spittal, P.M., Small, W., Tyndall, M.W., O’shaughnessy, M.V., Schecter, M.T. (2003). An external evaluation of a peer-run "unsanctioned" syringe exchange Program. Journal of Urban Health, 80(3), 455-464. 


\section{Figures}

Figure 1. Main component of the Downtown Eastside harm reduction network $(\mathrm{n}=1131)$

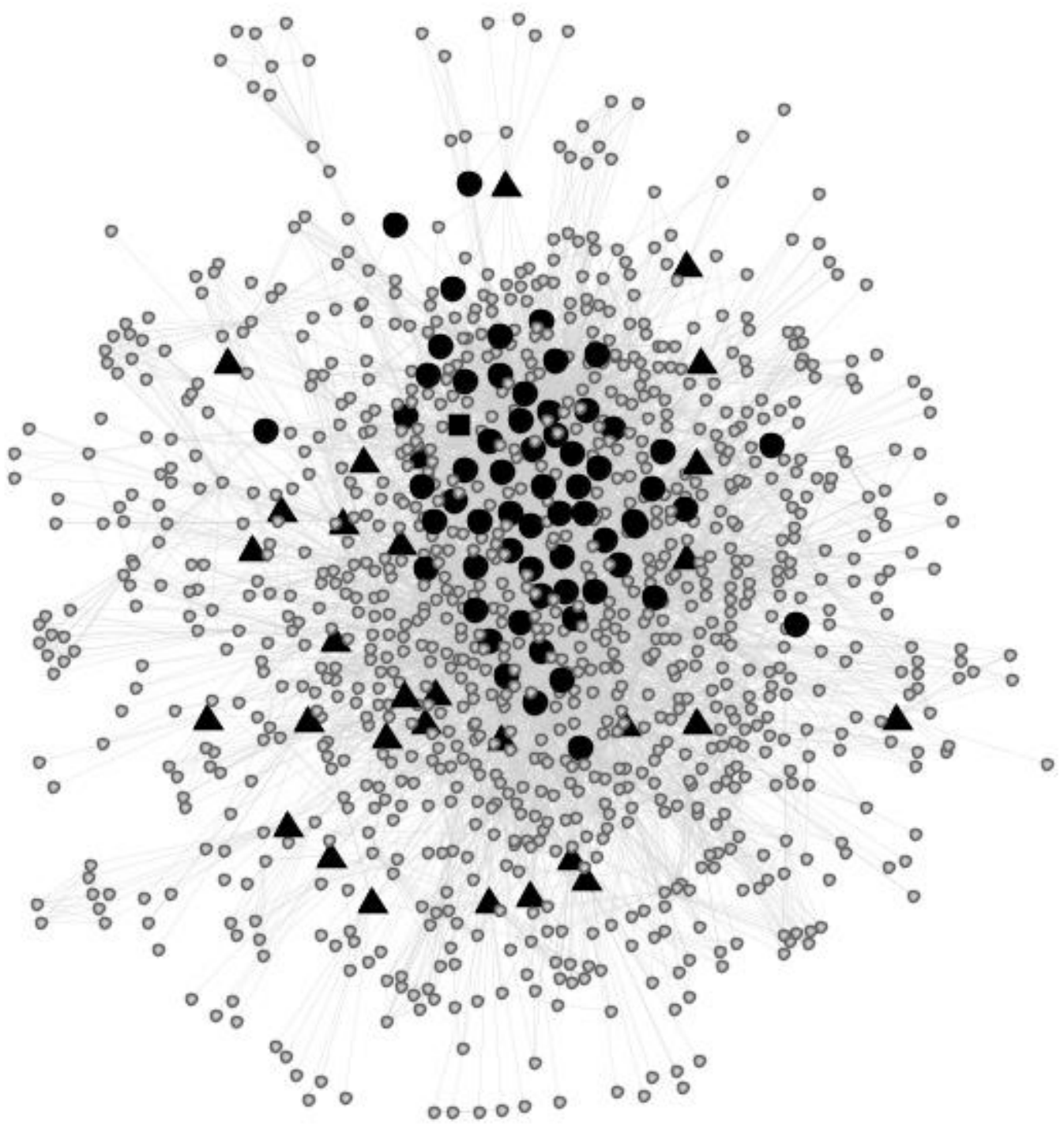

Notes. Main component shown $(\mathrm{n}=1131)$, a small isolated component of four nodes removed. Circles: Core members $(n=62)$; Triangles: Articulation Points $(n=30)$; Square: Both articulation point and core member $(n=1)$ 


\section{Tables}

Table 1. Descriptive statistics and bivariate comparisons for respondents across the sites $(\mathbf{n}=199)$

\begin{tabular}{|c|c|c|c|}
\hline Socio-Demographics & $\begin{array}{c}\text { InSite and VANDU } \\
(\mathrm{n}=199) \\
\% \text { or M (SD) }\end{array}$ & $\begin{array}{c}\text { InSite } \\
(\mathrm{n}=100) \\
\% \text { or M (SD) } \\
\end{array}$ & $\begin{array}{c}\text { VANDU } \\
(n=99) \\
\% \text { or M (SD) } \\
\end{array}$ \\
\hline Age & $44.47(10.41)$ & $44.88(10.92)$ & $44.05(9.92)$ \\
\hline Male $(=1) *$ & 61.3 & 70.0 & 52.5 \\
\hline Single $(=1)$ & 67.8 & 66.0 & 69.7 \\
\hline Caucasian & 59.8 & 66.0 & 53.5 \\
\hline Heterosexual (=1) & 94 & 93.0 & 94.9 \\
\hline High school graduate $(\mathrm{n}=1)$ & 56.3 & 56.0 & 56.6 \\
\hline Unemployed $(\mathrm{n}=1)$ & 68.3 & 67.0 & 69.7 \\
\hline Criminal record $(=1)$ & 78.4 & 82.0 & 74.7 \\
\hline \multicolumn{4}{|l|}{ Medical condition } \\
\hline HIV Positive $(\mathrm{n}=1)$ & 13.1 & 10.0 & 16.2 \\
\hline HCV Positive ( $\mathrm{n}=1)$ & 53.8 & 50.0 & 57.6 \\
\hline \multicolumn{4}{|l|}{ Drug use } \\
\hline Heroin (=1) & 81.4 & 84.0 & 78.8 \\
\hline Ever overdose (=1) & 45.2 & 40.0 & 50.5 \\
\hline All new syringes $(=1)$ & 92.0 & 91 & 92.9 \\
\hline Number of years injected & $17.45(12.10)$ & $17.57(12.20)$ & $17.33(12.06)$ \\
\hline Number of injections, per week & $42.32(43.60)$ & $41.02(39.58)$ & $43.62(47.49)$ \\
\hline Money spent on drugs, weekly (log) & $6.06(1.71)$ & $5.90(2.15)$ & $6.22(1.10)$ \\
\hline
\end{tabular}

Notes:

Statistical differences were determined using Pearson chi-square for categorical variables. Fischer used in lieu of Pearson when expected count less than 5. T-Test used for age and years of drug use " p $<0.05$ (two tailed tests). 
Table 2. Descriptive statistics and bivariate comparisons for contacts within the sites $(\mathbf{n = 1 0 2 5})$

\begin{tabular}{|c|c|c|c|c|c|}
\hline & & $\begin{array}{c}\text { Overall } \\
(n=1025) \\
\% \text { or M (SD) } \\
\end{array}$ & $\begin{array}{c}\text { InSite and VANDU } \\
(\mathrm{n}=153) \\
\% \text { or M (SD) }\end{array}$ & \begin{aligned} & \multicolumn{1}{|c|}{ InSite } \\
&$(\mathrm{n}=433) \\
& \%$ or $M(\mathrm{SD}) \\
&\end{aligned}$ & $\begin{array}{c}\text { VANDU } \\
(n=439) \\
\% \text { or } M(S D) \\
\end{array}$ \\
\hline Contacts $(n=1025)$ & Total $n$ & & & & \\
\hline Age* & 1023 & $40.45(12.02)$ & $41.78(9.51)$ & $39.01(13.43)$ & $41.4(11.20)$ \\
\hline Male $(=1) *$ & 1025 & 60.1 & 68.6 & 61.9 & 55.4 \\
\hline Heroin $(=1) *$ & 1025 & 56.9 & 91.5 & 41.3 & 60.1 \\
\hline Years of drug use & 895 & $12.99(10.34)$ & $14.18(7.73)$ & $12.04(11.68)$ & $13.27(10.07)$ \\
\hline Still uses $(=1) *$ & 1010 & 75.6 & 93.5 & 57.1 & 90.1 \\
\hline Ever used $(=1) *$ & 1025 & 80.4 & 96.7 & 64.7 & 90.2 \\
\hline HIV Positive $(=1) *$ & 1025 & 11.4 & 20.9 & 5.8 & 13.7 \\
\hline $\operatorname{HCV}$ Positive $(=1) *$ & 1025 & 29.5 & 52.9 & 22.6 & 28 \\
\hline Mentor $(=1) *$ & 1025 & 23.7 & 43.8 & 24.9 & 15.5 \\
\hline
\end{tabular}

Notes:

Statistical difference across the three groups (those in VANDU, InSite and those present in both sites) determined using ANOVA and Pearson chi-square tests, ${ }^{*} \mathrm{p}<0.05$ (two tailed tests) 
Table 3. Descriptive characteristics and bivariate comparisons between core and non-core network members, and articulation points and non-articulation points

\begin{tabular}{lcc|cc}
\hline & $\begin{array}{c}\text { Non-Core } \\
\text { \% or M (SD) }\end{array}$ & $\begin{array}{c}\text { Core } \\
\text { \% or M (SD) }\end{array}$ & $\begin{array}{c}\text { Non-Articulation } \\
\text { Point } \\
\text { \% or M (SD) }\end{array}$ & $\begin{array}{c}\text { Articulation } \\
\text { Point } \\
\text { \% or M (SD) }\end{array}$ \\
\hline $\mathrm{N}$ & 1068 & 63 & 1100 & 31 \\
\hline$\%$ respondents & $16.5 \%$ & $34.9 \% * * *$ & $15.4 \%$ & $93.5 \% * * *$ \\
Age & $40.51(12.08)$ & $44.52(8.20)^{* *}$ & $40.72(11.97)$ & $41.45(10.80)$ \\
Male (=1) & 59.0 & $73.0^{*}$ & 60.4 & $38.7^{*}$ \\
Heroin (=1) & 57.0 & $82.5^{* * *}$ & 57.9 & $77.4^{*}$ \\
Years of drug use & $12.93(10.42)$ & $14.0(8.70)$ & $12.97(10.36)$ & $14.6(7.42)$ \\
Still uses (=1) & 76.8 & 74.6 & 76.5 & 92.9 \\
Ever used (=1) & 82.0 & 87.3 & 81.9 & $96.8^{*}$ \\
HIV Positive (=1) & 11.2 & 15.9 & 11.6 & 6.5 \\
HCV Positive (=1) & 30.0 & $54.0^{* * *}$ & 30.5 & $64.5^{* * *}$ \\
Mentor (=1) & 18.4 & $73.0^{* * *}$ & 21.7 & 12.9 \\
Both & & & & 16.1 \\
VANDU/InSite & 10.6 & $63.5 * * *$ & 13.5 & \\
\hline
\end{tabular}

Notes. Pearson Chi square used for categorical variables. Fischer in lieu of Pearson when expected count less than 5. T-Test used for age and years of drug use

${ }^{*} \mathrm{p}<0.05$ (two tailed tests) ${ }^{* * *} \mathrm{p}<0.01$ (two tailed tests) ${ }^{* * * *} \mathrm{p}<0.001$ (two tailed tests). 
Table 4. Descriptive characteristics and bivariate comparisons between those reached by articulation points and those not reached, those impacted by the removal of articulation points and those not impacted

\begin{tabular}{|c|c|c|c|c|}
\hline & \multicolumn{2}{|c|}{ Articulation Point } & \multicolumn{2}{|c|}{ Removal of Articulation Points } \\
\hline & $\begin{array}{c}\text { Reached } \\
\% \text { or M (SD) } \\
\end{array}$ & $\begin{array}{l}\text { Not Reached } \\
\text { \% or M (SD) } \\
\end{array}$ & $\begin{array}{c}\text { Isolated Nodes } \\
\% \text { or M (SD) } \\
\end{array}$ & $\begin{array}{c}\text { Non-Isolated Nodes \% } \\
\text { or M (SD) } \\
\end{array}$ \\
\hline $\mathrm{N}$ & 416 & 715 & 39 & 1092 \\
\hline Age & $40.64(10.46)$ & $40.80(12.72)$ & $39.56(12.13)$ & $40.78(11.93)$ \\
\hline Male (= 1) & 60.1 & 59.6 & 41.0 & $60.4^{*}$ \\
\hline Heroin $(=1)$ & 65.1 & $54.6^{* *}$ & 48.7 & 58.8 \\
\hline Years of drug use & $12.49(9.26)$ & $13.35(10.98)$ & $9.60(9.02)$ & $13.13(10.35)$ \\
\hline Still uses $(=1)$ & 82.6 & $73.0 * * *$ & 79.5 & 76.6 \\
\hline Ever used $(=1)$ & 86.8 & $79.6^{*}$ & 82.1 & 82.3 \\
\hline HIV Positive (=1) & 12.7 & 10.7 & 5.1 & 11.7 \\
\hline HCV Positive $(=1)$ & 33.2 & 30.4 & 10.3 & $32.2 * *$ \\
\hline Mentor $(=1)$ & 26.9 & $18.3 * *$ & 17.9 & 21.6 \\
\hline
\end{tabular}

